\title{
A Cell Wall Integrity-Related MAP Kinase Kinase Kinase AfIBck1 Is Required for Growth and Virulence in Fungus Aspergillus flavus
}

\author{
Feng Zhang, ${ }^{1,2}$ Luhua Huang, ${ }^{1}$ Jili Deng, ${ }^{1}$ Can Tan, ${ }^{1}$ Longpo Geng, ${ }^{1}$ Yun Liao, ${ }^{1}$ Jun Yuan, ${ }^{1}$ \\ Shihua Wang ${ }^{1, \dagger}$ \\ ${ }^{1}$ Key Laboratory of Pathogenic Fungi and Mycotoxins of Fujian Province, Key Laboratory of Biopesticide and Chemical Biology \\ of Education Ministry, and School of Life Sciences, Fujian Agriculture and Forestry University, Fuzhou 350002, China \\ ${ }^{2}$ School of Biological Science and Biotechnology, Minnan Normal University, Zhangzhou 363055, China
}

Accepted 10 January 2020.

\begin{abstract}
Aspergillus flavus represents an important fungal pathogen, causing severe economic losses in crops. The mitogen-activated protein (MAP) kinase signaling pathway contributes to many physiological processes, but its precise role in $A$. flavus is not yet fully understood. In this study, we focused on the AflBck1 gene, which encodes a MAP kinase kinase kinase of the SIt2-MAPK pathway. Targeted deletion of $A f l B c k l$ led to a significant defect in growth and development, and a AflBckl-deleted mutant ( $\triangle A f l B c k 1)$ showed higher sensitivity to cell-wall stress than wild type (WT). Importantly, we observed that $\Delta A f l B c k 1$ displayed an enhanced ability to produce aflatoxin, a potential carcinogenic mycotoxin. However, the pathogenicity of the $\Delta A f l B c k 1$ mutant was markedly reduced in peanut seeds. We also presented evidence that AflBck1 was genetically epistatic to AflMkk2 in the SIt2-MAPK pathway. Finally, we found that loss of the proline-rich region at the $\mathbf{N}$ terminus of AflBck1 affected the reproduction of $\boldsymbol{A}$. flavus. Collectively, this study not only extended the understanding that the MAPK pathway regulated $A$. flavus pathogenicity but also provided a possible strategy to control $A$. flavus contamination.
\end{abstract}

Keywords: aflatoxin, Aspergillus flavus, mitogen-activated protein kinase pathway, pathogenicity

The mitogen-activated protein (MAP) kinase cascade is a critical signal pathway controlling various physiological processes related to growth, adaptation, and pathogenesis in fungal pathogens (Jiang et al. 2018). In general, this cascade consists of three protein kinases: MAP kinase kinase kinase (MAPKKK), MAPKK, and MAPK. A MAPKKK phosphorylates and activates the MAPKK, which in turn activates the downstream

Feng Zhang, Luhua Huang, and Jili Deng contributed equally to this work.

${ }^{\dagger}$ Corresponding author: S. Wang; wshyyl@ sina.com

Funding: Funding was provided for this research from the grants of the National Natural Science Foundation of China (number 31400100).

*The $\boldsymbol{e}$-Xtra logo stands for "electronic extra" and indicates that three supplementary figures and four supplementary tables are published online.

The author(s) declare no conflict of interest.

๑) 2020 The American Phytopathological Society
MAPK. In the budding yeast Saccharomyces cerevisiae, there are five MAPK pathways that involve mating (Fus3), filamentous growth (Kss1), high osmolarity response (Hog1), cell wall integrity (CWI) (Slt2), and spore formation (Smk1) (Molina et al. 2010). Except for the Smk1-MAPK components, other yeast MAPK members have been more or less characterized in plantpathogenic ascomycetes (Jiang et al. 2018). In the rice blast fungus Magnaporthe grisea, three different orthologs of yeast MAPK have been characterized, two of which play important roles in pathogenicity (Xu 2000). In the wheat scab fungus Fusarium graminearum, the Fus3 ortholog (Gpmk1) is essential for infectious growth, while the Slt2 ortholog (Mgv1) is indispensable for hyphal fusion (Zhao et al. 2007). However, in Aspergillus flavus, only Hog1-MAPK pathway genes have so-far been reported critical for growth and pathogenicity (Tumukunde et al. 2019; Yuan et al. 2018).

A. flavus is an important fungal pathogen of many economically crops, such as corn, cotton, and peanuts. As a soil-borne fungus, A. flavus can contaminate pre- and postharvest crops. A. flavus is also a human pathogen causing allergic bronchopulmonary aspergillosis (Klich 2007). A. flavus grows over the 12 to $48^{\circ} \mathrm{C}$ range, but growth rate is fastest at $37^{\circ} \mathrm{C}$ (Hedayati et al. 2007). Water activity $\left(\mathrm{a}_{\mathrm{w}}\right)$ was also found to be a pivotal factor for growth (Zhang et al. 2014). Under the right conditions, the fungus has the ability to produce mycotoxins on infested crops, notably aflatoxins. Aflatoxins are secondary metabolites that cause acute death, liver cancer, and immune suppression in both animals and humans. It has been estimated that annual economic losses in the corn industry caused by aflatoxin contamination reaches up to $\$ 1.68$ billion in the United States (Mitchell et al. 2016). Although the gene cluster for aflatoxin biosynthesis was revealed a long time ago, the precise mechanism of how A. flavus regulates the aflatoxin cluster to produce toxin is not completely understood (Nie et al. 2018). In our opinion, this may be the biggest obstacle to control aflatoxin contamination effectively.

The aflatoxin production of $A$. flavus was found to be regulated by several pathways (Georgianna and Payne 2009). Recently, our laboratory has demonstrated that the Hog1-MAPK pathway is involved in the regulation of aflatoxin biosynthesis in A. flavus (Yuan et al. 2018; Tumukunde et al. 2019). As a MAPKK of Hog1-MAPK pathway, PbsB positively regulates aflatoxin generation. Interestingly, sakA/hogA, the MAPK of the Hog1-MAPK pathway, plays an opposite role in aflatoxin biosynthesis. This inconsistency suggests the complexity in regulation of aflatoxin synthesis by the Hog1-MAPK pathway. 
However, no element of Sit2-MAPK pathway has been defined in A. flavus to date. In this study, we described AflBck1, the most upstream component of the Slt2-MAPK pathway, from the aflatoxin producer $A$. flavus. Our results showed that, like an ortholog of yeast Bck1, AflBck1 played important roles in maintaining CWI and sensing environment stresses. Our study also revealed its functions on aflatoxin biosynthesis and fungal pathogenesis. The present study may be useful to dissect the regulation mechanism of aflatoxin biosynthesis and controlling of A. flavus contamination.

\section{RESULTS}

\section{AflBckl encodes a putative MAPKKK}

of the SIt2-MAPK pathway in A. flavus.

The Slt2-MAPK pathway regulates diverse physiological processes in fungi ( $\mathrm{Xu} 2000)$. In order to investigate the function of this pathway in A. flavus, we selected a Bck1 homolog, the most upstream component of the Slt2-MAPK pathway in yeast, from A. flavus. Using the protein sequence of ScBck1 (CAA89389.1) as a query, we identified a Bck1 homolog (RMZ40061) from the A. flavus genome. With a similar approach, we obtained the Bck1 homolog from A. oryzae (XM_023234981.1), A. niger (XP_001399818), A. fumigatus (XM_749418.1), A. nidulans (XM_657399.1), Neurospora crassa (XP_011395112.1), Magnaporthe oryzae (XP_003718085.1), and Candida albicans (XP_716984.2). Protein sequence alignment results showed that AflBck1 had high sequence similarity to other fungal Bck1 homologs (Fig. 1A). Sequence analysis revealed that AflBck1 contained a highly conserved serine/ threonine protein kinase catalytic domain at the carboxy terminus (Fig. 1B). Interestingly, at the N-terminus, AflBck1 possesses a proline-rich region (PRR) from all filamentous fungi, suggesting a conserved function of this region. Based on this information, AflBck1 could be classified into the MAPKK kinase of Slt2-MAPK pathway.

\section{$A f l B c k 1$ is required for hyphal growth.}

In order to gain insight in the biological function of the AflBckl gene, the AflBckl deletion mutant and complementation strain were constructed using a previous method (Zhang et al. 2018) (Supplementary Fig. S1A). After confirmation by PCR, reverse transcription PCR (RT-PCR), and Southern blot analysis (Supplementary Fig. S1B, C, and D), AflBckl deletion mutant ( $\triangle A f l B c k 1)$, complementation strain (AflBcklcom), and the wild-type (WT) strain were cultured on yeast extract-sucrose (YES) and potato dextrose agar (PDA) medium. As shown in

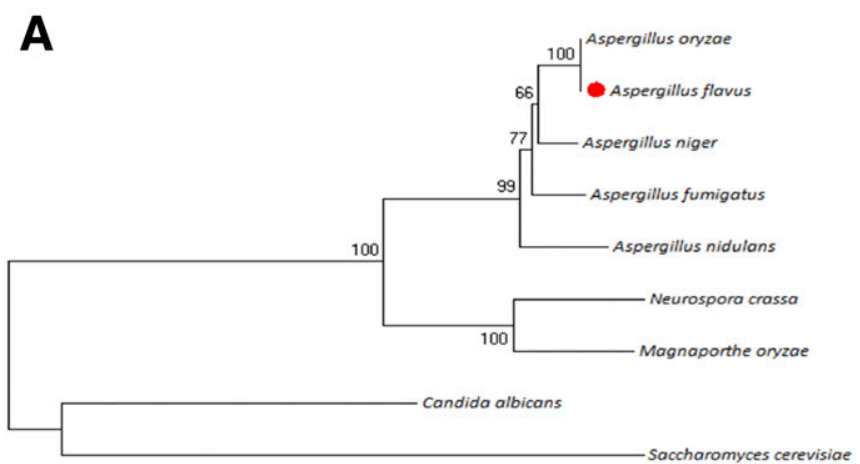

0.5
Figure 2A, $\triangle A f l B c k 1$ displayed severely retarded growth and a shriveled colony with an irregular margin. A magnified view of the colony margin revealed that hyphae of $\triangle A f l B c k 1$ formed some swollen structures in contrast to the smooth hyphae of WT and AflBcklcom (Fig. 2B). It has been known that hydrophobicity of the aerial mycelia affects fungal colony morphology (Talbot 1997). When applying $10 \mu \mathrm{l}$ of $2.5 \%$ bromophenol blue to the mycelial surface, the droplet was partly absorbed by mycelial mats of the $\triangle A f l B c k 1$ mutant but not by WT and AflBcklcom (Fig. 2C), indicating defective hydrophobicity of the aerial mycelia in mutants. All these results clearly showed that AflBck1 was required for hyphal development.

\section{$A f l B c k 1$ is important for conidia and sclerotia formation.}

For A. flavus, asexual conidia are crucial players in infecting hosts. Here, we observed that WT and AflBcklcom produced an abundance of conidia on YES and PDA medium while $\triangle A f l B c k 1$ nearly lost the ability to produce conidia (Fig. 3A). Conidia of $A$. flavus are produced by the conidiophore, which is formed by the swollen hypha apex (Bojović-Cvetić and Vujičić 1974). As anticipated, the $\triangle A f l B c k 1$ mutant failed to form conidiophore, whereas WT and AflBcklcom produced bushy conidiophores (Fig. 3B). Both $a b a A$ and $b r l A$ are necessary genes for Aspergillus spp. to complete conidiophore development (Krijgsheld et al. 2013). Thus, we tested whether the expression of genes $a b a A$ and $b r l A$ in the $\triangle A f l B c k l$ strain was dropped. Unsurprisingly, quantitative PCR results fully confirmed our guess that the expression levels of $a b a A$ and $b r l A$ genes in the $\triangle A f l B c k l$ strain were lower than WT and AflBcklcom (Fig. 3C).

Apart from conidia, A. flavus has the ability to produce sclerotium, which is an important survival structure under adverse conditions. On Wickerham medium (WKM), WT and AflBcklcom could produce an abundance of sclerotia buried in white hyphae (Fig. 4A and B). On the other hand, the $\triangle A f l B c k l$ strains failed to produce sclerotium (Fig. 4A and B). Based on the key roles of $n s d C$ and $n s d D$ in sclerotia formation (Cary et al. 2012), we analyzed the transcription levels of these two genes in A. flavus. Our results demonstrated that the $\triangle A f l B c k 1$ strain had fewer transcripts of $n s d C$ and $n s d D$ than did WT and AflBcklcom (Fig. 4C). The combined data demonstrated that AflBckl was an important regulator in conidia and sclerotia formation.

\section{AflBck1 maintains CWI.}

To determine whether $A f l B c k 1$ is linked to CWI, we cultured A. flavus on YES media supplemented with different cell-wall inhibitors. The results showed that all cell wall-damaging agents were able to inhibit the radial growth of WT, $\triangle A f l B c k l$,

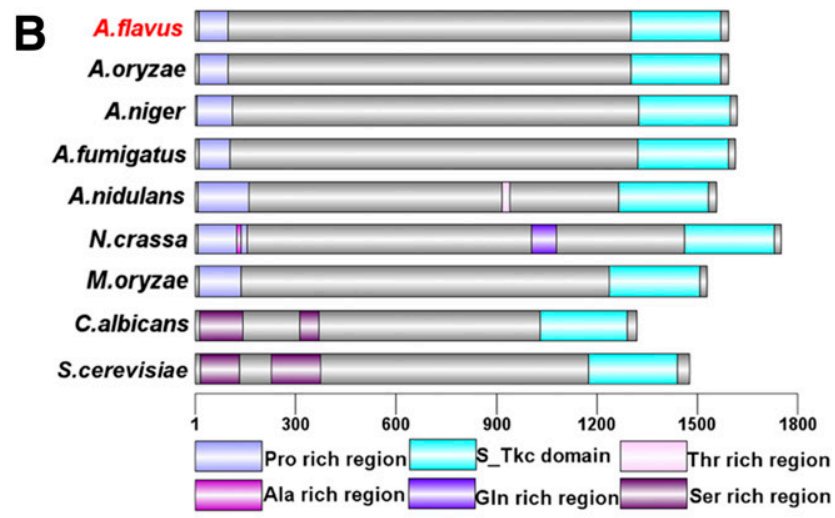

Fig. 1. Bioinformatic analysis of Bck1 protein from different fungi. A, The phylogenetic tree based on all the Bck1 protein sequences from different organisms was constructed, by MEGA7.0 software, using the neighbor-joining method. Bootstrap analysis was performed with 1,000 replicates. B, Protein sequence structure of Bck1 was identified by SMART and ScanProsite tools and the domain architectures were visualized using software DOG 2.0. 

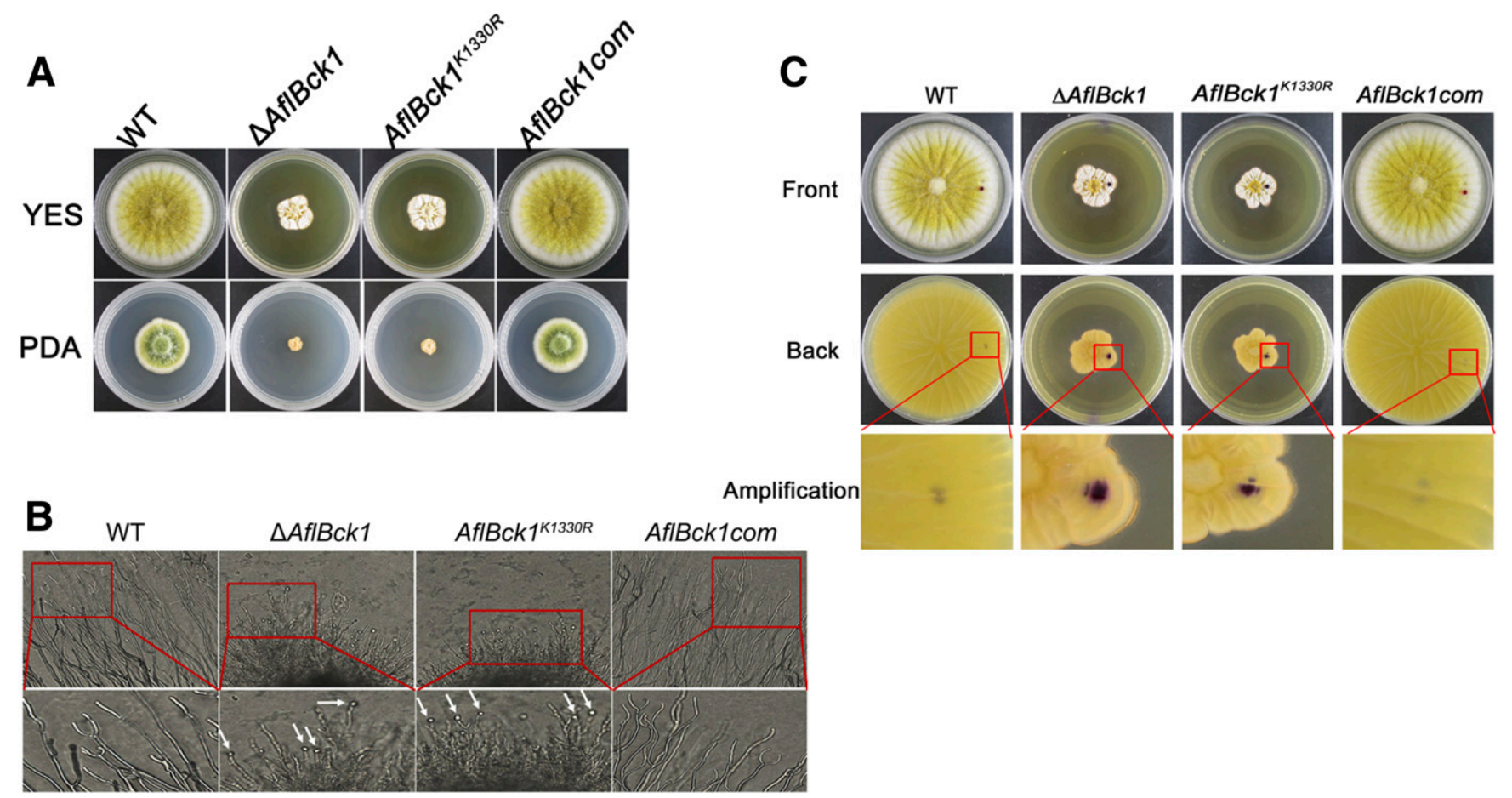

Fig. 2. Effects of AflBck1 on hyphal growth. A, Colonies morphology of wild type (WT), $\triangle A f l B c k 1, A f l B c k 1^{K 1330 R}$, and $A f l B c k 1$ com strains cultured on yeast extract-sucrose (YES) and potato dextrose agar (PDA) solid media at $37^{\circ} \mathrm{C}$ for 4 days. B, Mycelial tips of WT, $\triangle A f l B c k 1, A f l B c k 1^{K 1330 R}$, and $A f l B c k 1 c o m$ strains observed by light microscope after incubation for $12 \mathrm{~h}$. White arrows indicate swollen structures at the tip of hyphae. C, Hydrophobicity tests of WT, $\triangle A f l B c k 1, A f l B c k 1^{K 1330 R}$, and AflBcklcom strains cultured on YES solid media.
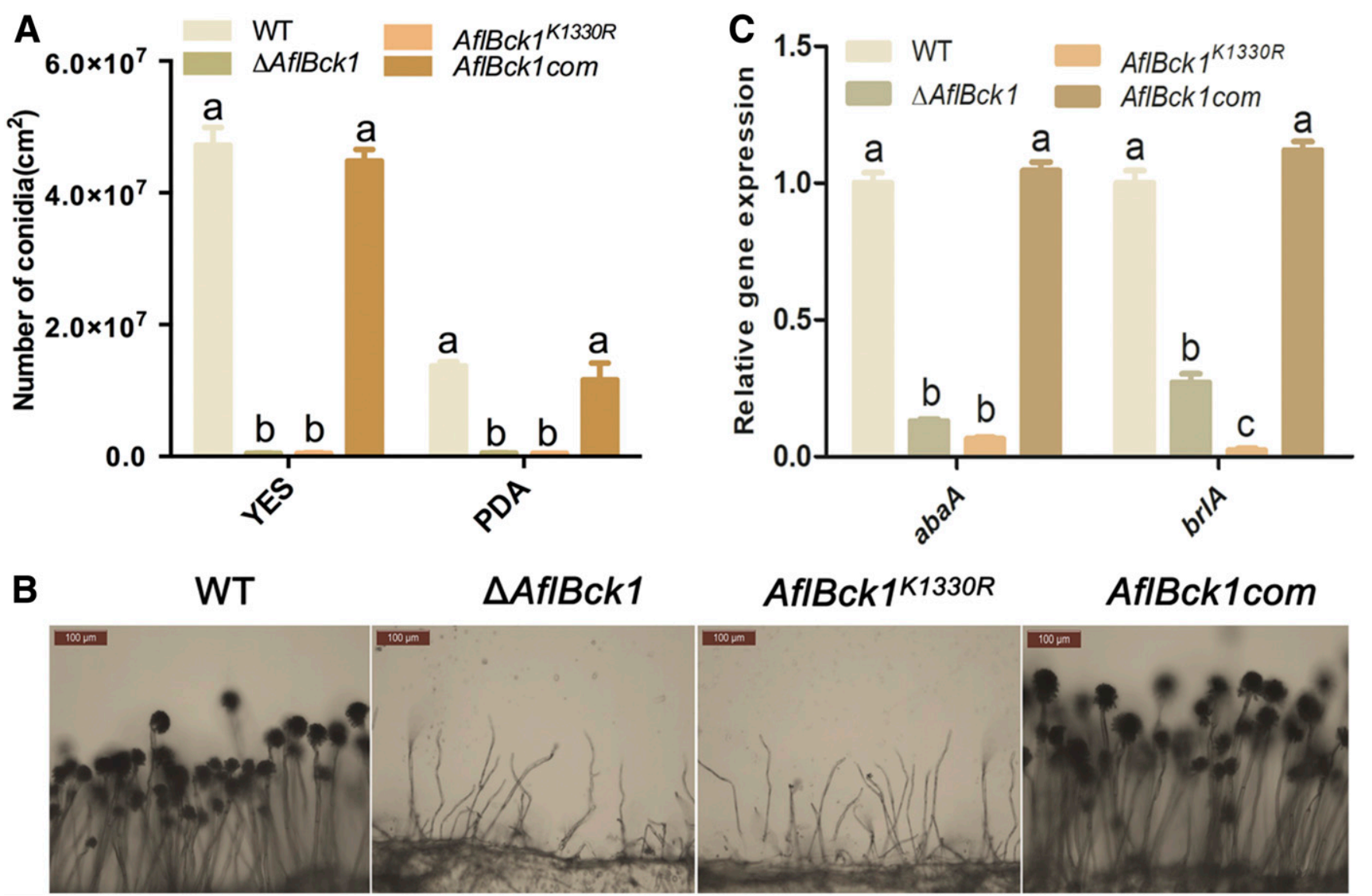

AflBck1K1330R

AflBck1com

Fig. 3. Conidiation analysis of Aspergillus flavus strains. A, Quantitative analysis of conidia on yeast extract-sucrose (YES) and potato dextrose agar solid media at $37^{\circ} \mathrm{C}$ for 4 days. B, Microscopic analysis of conidiophores on YES media after incubation for $12 \mathrm{~h}$, bars $=100 \mu \mathrm{m}$. $\mathbf{C}$, Quantitative reverse transcription PCR analysis of conidiation-related genes brlA and $a b a A$ on YES solid media after incubation for $48 \mathrm{~h}$ at $37^{\circ} \mathrm{C}$. Different letters above the bars represent significant difference $(P<0.001)$. 
and AflBcklcom (Fig. 5A and B). However, we observed that the growth inhibition rate of $\triangle A f l B c k 1$ in additive media was markedly higher than those of WT and AflBcklcom (Fig. 5A and B). As glucan and chitin are two major components of the cell wall, we hypothesize that AflBck1 impacts on glucan and chitin synthesis. To test this hypothesis, we quantified the expression levels of one glucan synthase (AFLA_023460) and four chitin synthase (AFLA_114760, AFLA_013690, AFLA_136030, and AFLA_060590) genes. As shown in Figure 5C, under Congo red stress, the expression levels of five cell wall synthesis-related genes in $\triangle A f l B c k 1$ were significantly lower than those in WT and AflBcklcom. These results demonstrated that the AflBckl knockout strain was compromised in maintaining CWI.

\section{AflBckl has an adverse effect on oxidation tolerance.}

Considering that oxidative stress is another important environment stimuli during fungi survival (Moye-Rowley 2003), we questioned whether AflBck1 participated in responding to this stress. To address this question, WT, $\triangle A f l B c k l$, and AflBcklcom strains were equally inoculated into YES medium amended with different concentrations of hydrogen peroxide for 2 days. As anticipated, the WT and AflBcklcom grew slower when the concentration of hydrogen peroxide rose (Fig. 6A). Otherwise, no significant difference of vegetative growth was observed when the $\triangle A f l B c k l$ strain was grown on YES medium with different concentration of hydrogen peroxide (Fig. 6A). In agreement, the inhibitory effect of hydrogen peroxide on the growth of the WT and AflBcklcom was stronger than that of the $\triangle A f l B c k 1$ strain (Fig. 6B). In trying to understand this phenomenon, we tested the relative expression of two reactive oxygen species (ROS) scavenging enzymes (CAT2 and SOD) in all three strains. The result showed that the transcription levels of both genes in the $\triangle A f l B c k l$ strain were higher than that of the WT and AflBcklcom (Fig. 6C). By summarizing these results, we conclude that AflBck1 plays a negative role in the regulation of oxidative response.

\section{AflBck1 negatively regulates aflatoxin biosynthesis.}

To examine whether the disruption of AflBckl affects aflatoxin biosynthesis, conidial suspensions of WT, $\triangle A f l B c k l$, and AflBcklcom were inoculated into YES broth. Thin-layer chromatography (TLC) analysis results showed a significantly increased aflatoxin production in $\triangle A f l B c k l$ when compared with WT and AflBcklcom (Fig. 7A and B). AflC, AflD, AflM, AflO, $A f l P, A f l Q, A f l K, A f l S$, and $A f l R$ are essential genes in aflatoxin biosynthesis pathway (Yu et al. 2004). When we tested the expression levels of these genes, $\triangle A f l B c k l$ showed the highest expression levels of these genes among all three strains (Fig. 7C).
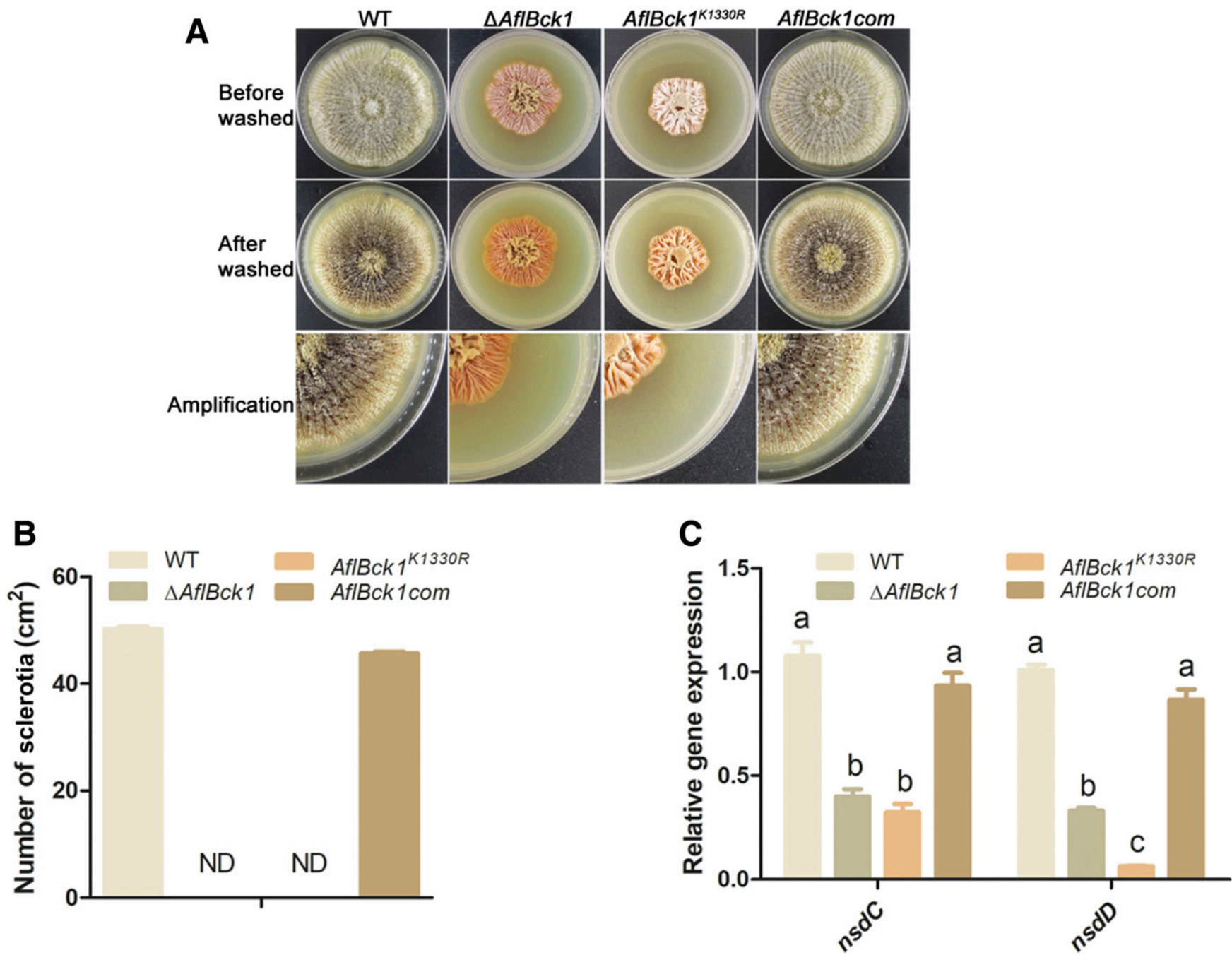

Fig. 4. Sclerotial formation of Aspergillus flavus strains. A, Sclerotial formation of different strains on Wickerham solid media (WKM) after grown for 7 days at $37^{\circ} \mathrm{C}$. B, Quantitative analysis of the sclerotia shown in A. C, Expression levels of sclerotia-related genes $n s d C$ and $n s d D$ in different strains on WKM solid media for $48 \mathrm{~h}$ at $37^{\circ} \mathrm{C}$. ND $=$ not detectable. Different letters above the bars represent significant difference $(P<0.001)$. 
These results lead us to conclude that $A f l B c k l$ influences aflatoxin biosynthesis through the downregulation of aflatoxin pathway genes.

\section{$A f l B c k 1$ is indispensable for fungal pathogenicity.}

A. flavus is a detrimental pathogen for many crops, which prompts us to test if lack of $A f l B c k l$ influences pathogenicity of A. flavus. Our pathogenicity assay showed that loss of AflBckl sharply reduced the colonization of $A$. flavus on peanuts (Fig. 8A). At the same time, the amount of conidia produced by $\triangle A f l B c k l$ on seeds was far fewer than that by WT and AflBcklcom (Fig. 8B). To investigate whether this defect in infection affects aflatoxin biosynthesis on seeds, we determined mycotoxin accumulation of the contaminated seeds. As evidence from the data in Figure $8 \mathrm{C}$ and $\mathrm{D}$, the $\triangle A f l B c k l$ produced more aflatoxin than WT and AflBcklcom. Thus, we favor the idea that AflBck1 is indispensable for colonization of A. flavus on seeds.

\section{AflBck1 is involved in the activation of the SIt2-MAPK pathway.}

Studies in $S$. cerevisiae have established that Bck1 is involved in the activation of Slt2-MAPK pathway (Widmann et al. 1999). To confirm the relationship between AflBck1 and Slt2-MAPK pathway, we measured the phosphorylation levels of Slt2 in the WT, $\triangle A f l B c k 1$, and AflBcklcom strains under Congo red stimulation. As illustrated in Figure $9 \mathrm{C}$, the phosphorylation levels of Slt2 in WT and AflBcklcom were enhanced under Congo red induction. As a comparison, no phosphorylation of Slt 2 occurred in the mutant $\triangle A f l B c k 1$, neither with nor without Congo red treatment (Fig. 9C). To exclude the possibility that AflBck1 affects the expression of Slt2, we checked the expression levels of Slt2 in the WT, $\triangle A f l B c k 1$, and AflBcklcom strains. Figure 9C shows that the Slt 2 levels in all three strains had no difference whether Congo red was present or not. In view of the results shown above, we believe that AflBck1 is involved in the activation of Slt2-MAPK pathway.

In Pneumocystis carinii, the kinase activity of Bck1 was abolished by changing the Lys ${ }^{574}$ to arginine (Thomas et al. 2003). Based on protein sequence alignments, we found that $\mathrm{Lys}^{574}$ is a highly conserved residue on Bck1 homologs from S. cerevisiae to A. flavus (Fig. 9A). To determine whether this residue on AflBck1 is a functional site, we created a point mutant $\left(A f l B c k 1^{K 1330 R}\right)$ by replacing the conserved lysine to an arginine (Fig. 9B). When we examined the phosphorylation levels of Slt2 in $A f l B c k 1^{K 1330 R}$ mutant, the results indicated that the phosphorylated Slt2 was vanished in $A f l B c k 1^{K 1330 R}$ mutant under unstressed condition (Fig. 9C). Interestingly, the mutant $A f l B c k 1^{K 1330 R}$ had a slightly phosphorylated Slt2 under stress

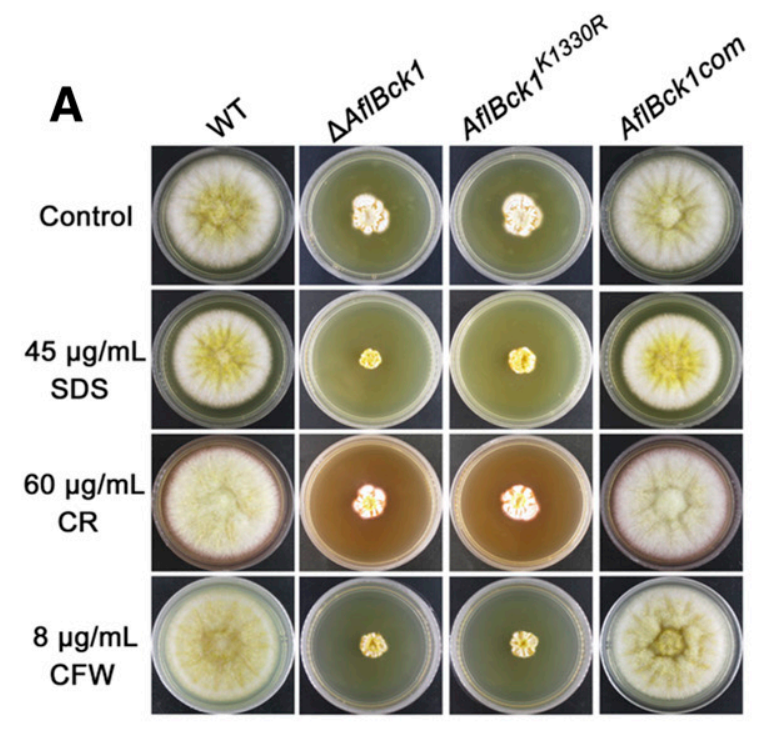

B
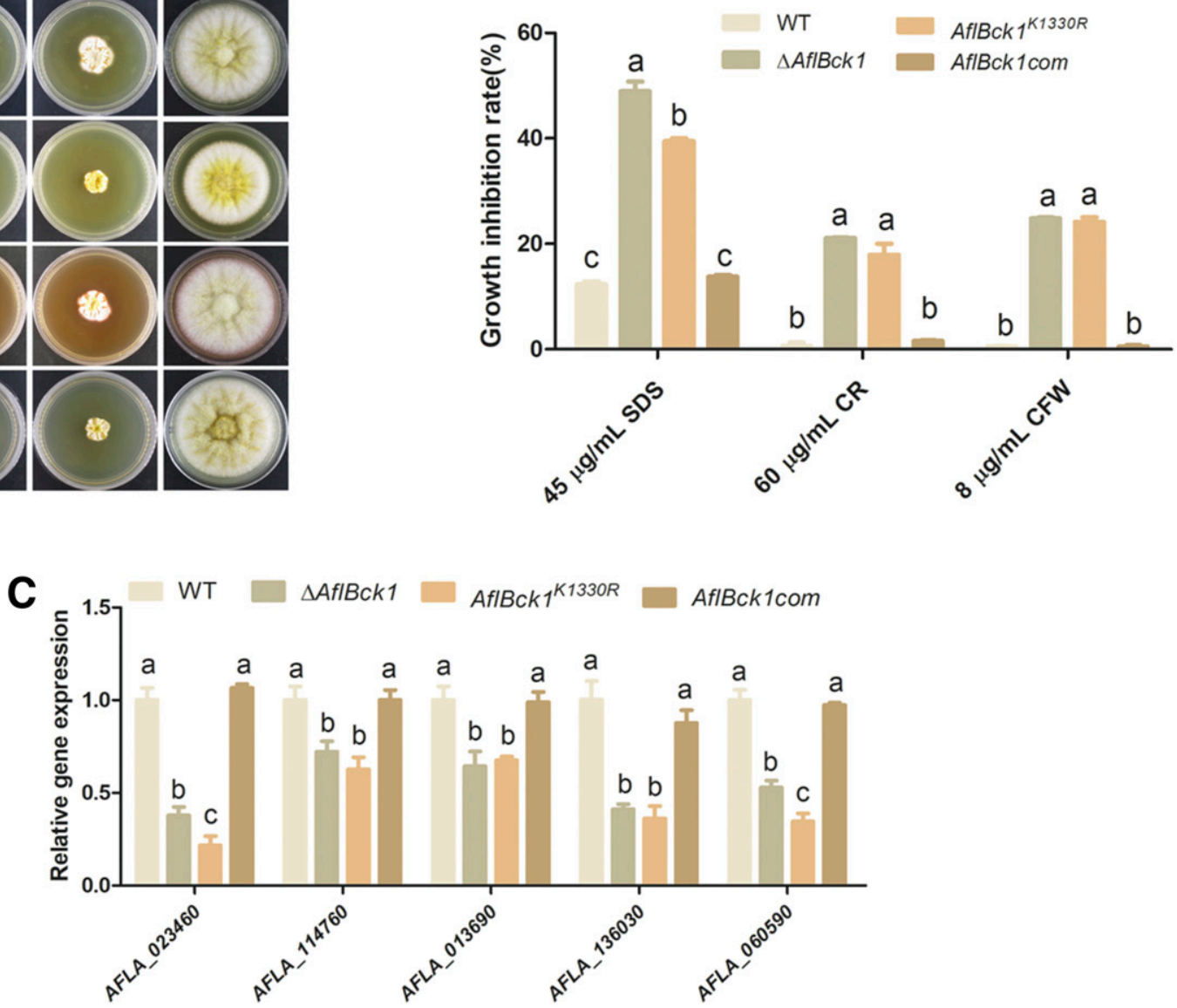

Fig. 5. Response of AflBck1 to cell wall stress. A, Colony morphology of the wild type (WT), $\triangle A f l B c k 1, A f l B c k 1^{K 1330 R}$, and AflBck1 com strains grown on yeast extract-sucrose (YES) solid media supplemented with sodium dodecyl sulfate (SDS), Congo red (CR), and Calcofluor white (CFW) at $37^{\circ} \mathrm{C}$ for 3 days. B, The inhibition rate of radial growth of strains shown in A. C, Relative transcript levels of cell wall synthesis-relevant genes in different strains on YES solid media containing $60 \mu \mathrm{g}$ of $\mathrm{CR}$ per milliliter for $72 \mathrm{~h}$ at $37^{\circ} \mathrm{C}$. Different letters above the bars represent significant difference $(P<0.001)$. 
conditions (Fig. 9C). Although not entirely as expected, these results confirmed that the Lys-1330 residue of AflBck1 is an important site for the phosphorylation of Slt2. Like $\triangle A f l B c k 1$, we found that the AflBck $1^{\text {K1330R }}$ mutant displayed defects in growth, development, response to stresses, aflatoxin biosynthesis, and fungal pathogenicity (Figs. 2, 3, 4, 5, 6, 7, and 8). Taken as a whole, we found that Lys ${ }^{1330}$ in AflBck1 was an essential residue for activation and full function in A. flavus.

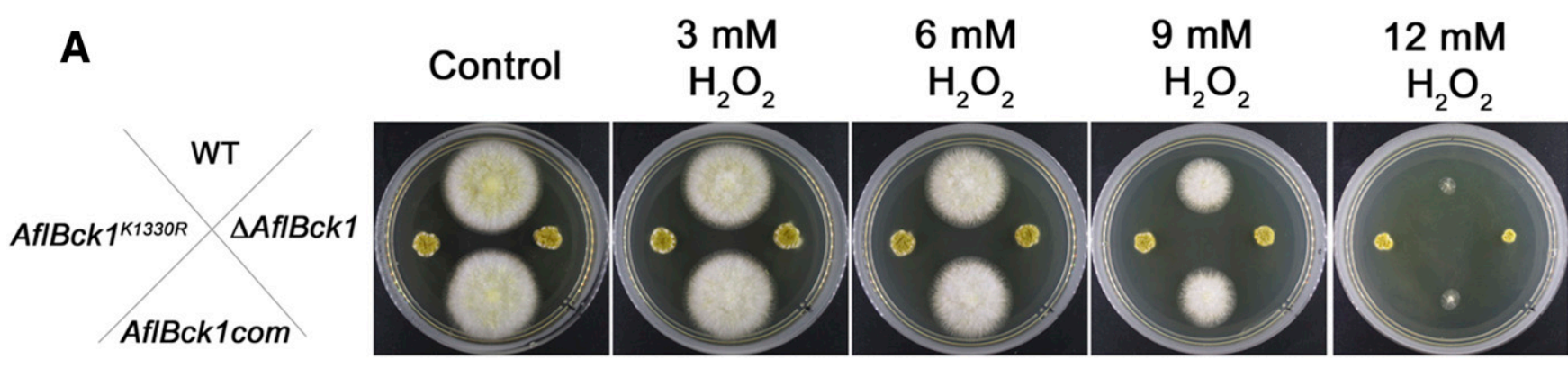

B

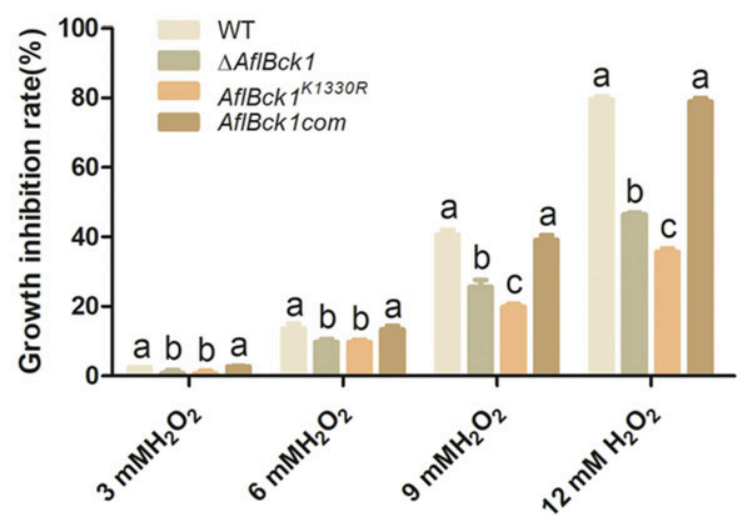

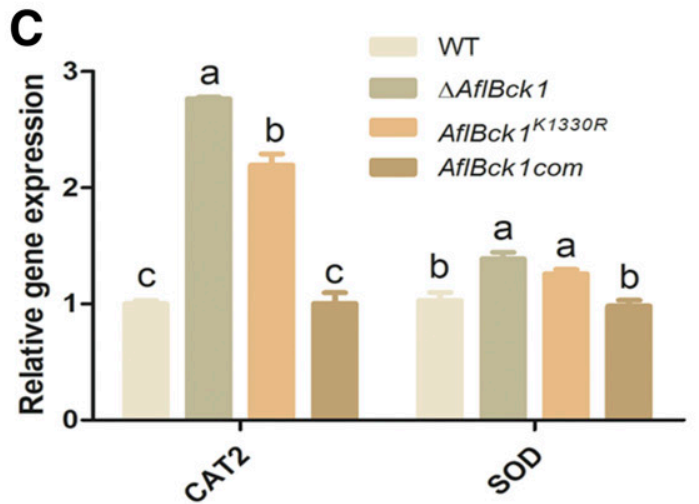

Fig. 6. Sensitivity of Aspergillus flavus strains to $\mathrm{H}_{2} \mathrm{O}_{2}$. A, Colony morphology of the wild type (WT), $\triangle A f l B c k 1, A f l B c k 1^{K 1330 R}$, and AflBcklcom strains grown on solid media of yeast extract-sucrose (YES) (Control) and YES containing the different concentrations of $\mathrm{H}_{2} \mathrm{O}_{2}$ at $37^{\circ} \mathrm{C}$ for 2 days. B, The inhibition rate of radial growth of strains shown in A. C, Relative transcript levels of two antioxidant genes in different strains on YES solid media containing $10 \mathrm{mM} \mathrm{H}_{2} \mathrm{O}_{2}$ medium for $72 \mathrm{~h}$ at $37^{\circ} \mathrm{C}$. Different letters above the bars represent significant difference $(P<0.001)$.
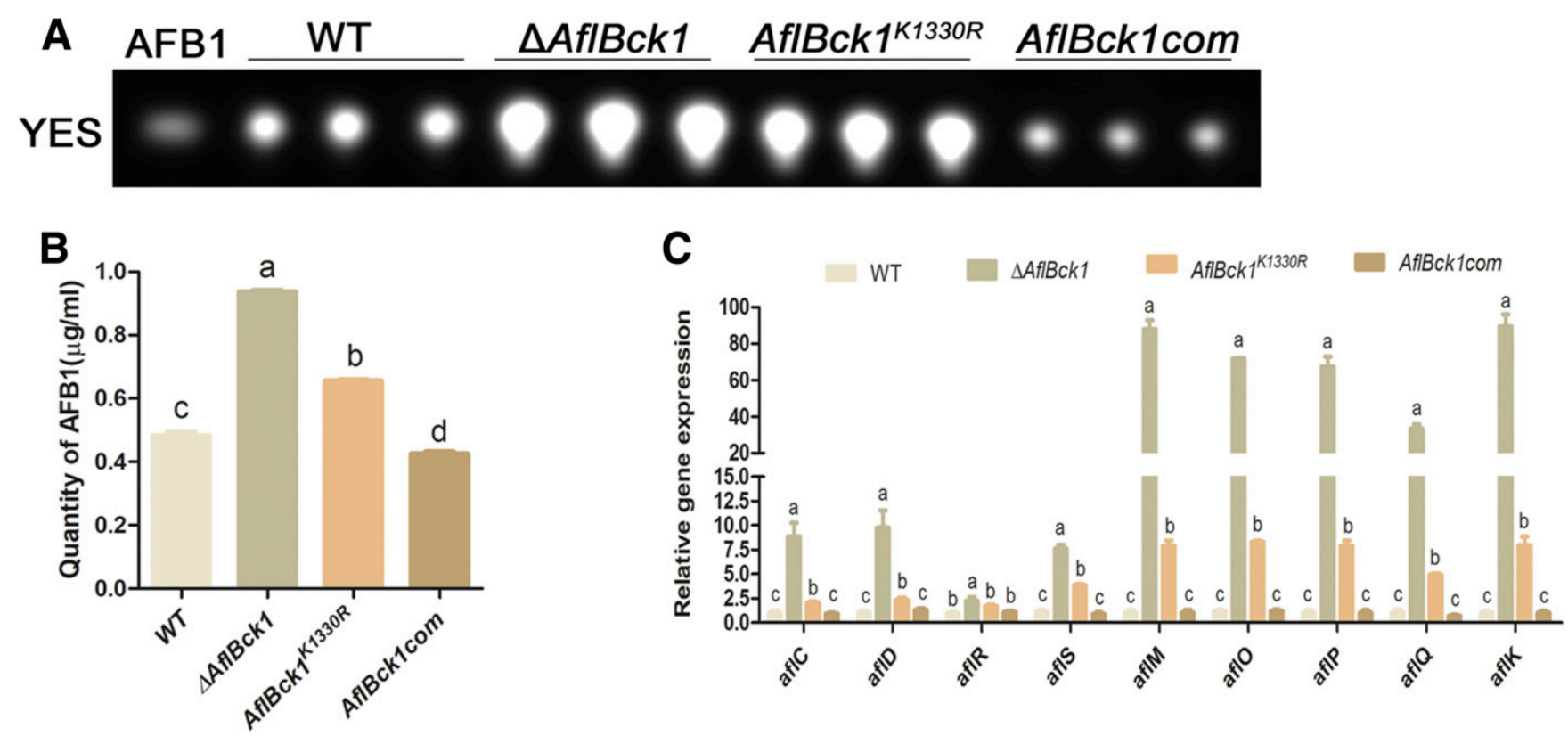

Fig. 7. Aflatoxin analysis of Aspergillus flavus strains. A, Thin-layer chromatography assay of AFB1 produced by wild type (WT), $\triangle A f l B c k 1, A f l B c k 1^{K 1330 R}$, and AflBcklcom strains in yeast extract-sucrose (YES) liquid media cultured at $29^{\circ} \mathrm{C}$ for 7 days. B, Quantification analysis of aflatoxin B1 (AFB1) from A. C, Relative transcript levels of nine aflatoxin biosynthesis-related genes in different strains cultured in YES liquid media for $72 \mathrm{~h}$ at $29^{\circ} \mathrm{C}$. Different letters above the bars represent significant difference $(P<0.001)$. 
AflBck1 is genetically epistatic to AflMkk2 in the SIt2-MAPK pathway.

Bearing in mind that Mkk2 is located downstream of Bck1 and upstream of Slt2 in yeast (Levin 2005), we wondered whether a constitutive activation of $M k k 2$ mutant could rescue the functional deficiency of $\triangle A f l B c k l$ mutant. For that, two constitutive-activation of $M k k 2$ mutants $\left(\triangle A f l B c k 1 / M k k 2^{D D}-3\right.$ and $\left.\triangle A f l B c k 1 / M k k 2^{D D}-12\right)$ were generated by replacing the
A
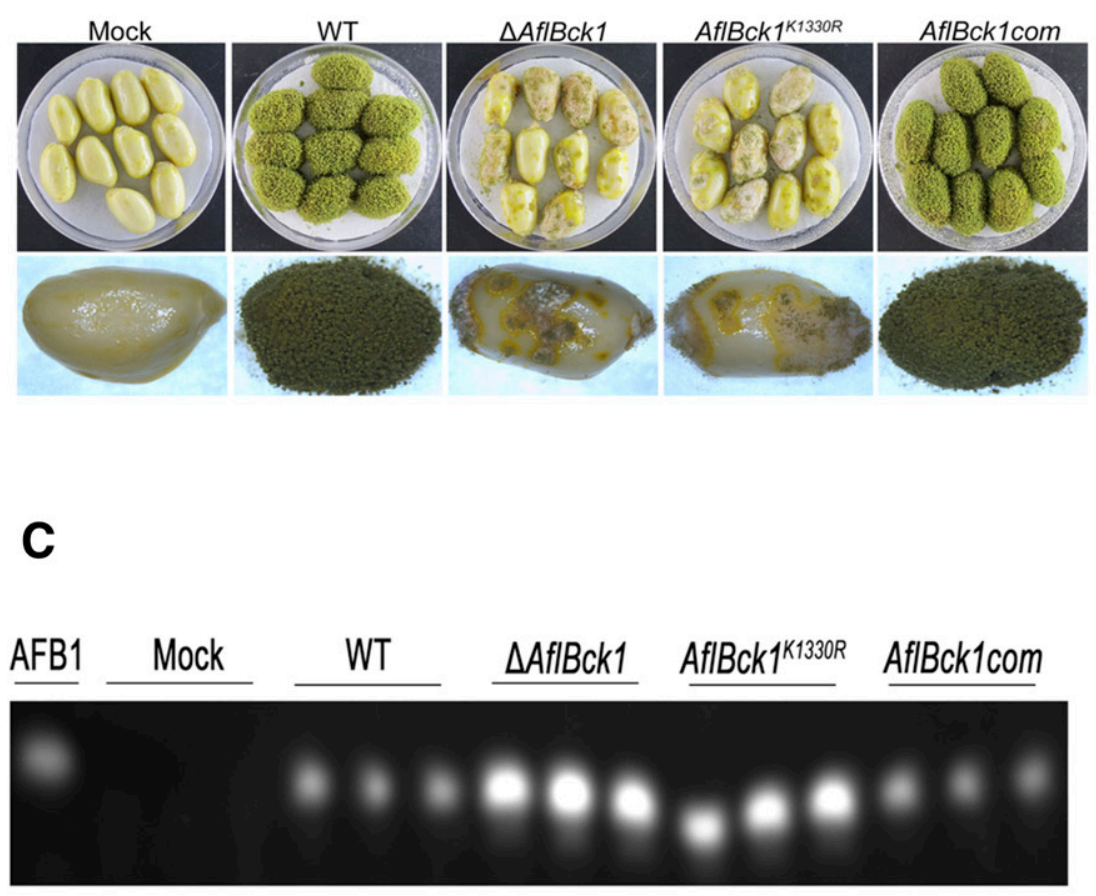

B

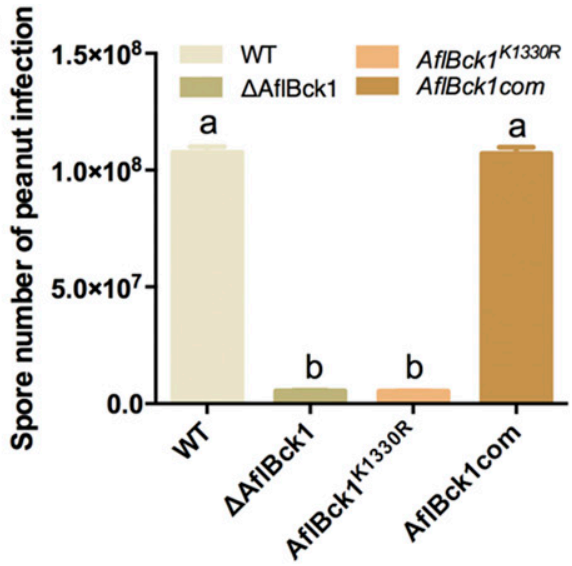

D

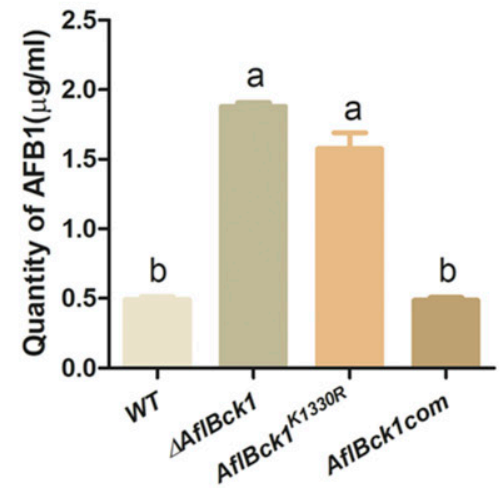

Fig. 8. Pathogenesis of Aspergillus flavus strains to peanuts. A, Colonization of wild type (WT), $\triangle A f l B c k 1, A f l B c k 1^{K 1330 R}$, and AflBcklcom strains on peanuts after 7 days of inoculation at $29^{\circ} \mathrm{C}$. B, Conidia production on peanuts shown in A. C, Thin-layer chromatography measurements of aflatoxin B1 (AFB1) extracted from peanuts shown in A. D, Quantification analysis of AFB1 shown in C. Different letters above the bars represent significant difference $(P<0.001)$.

A

\begin{tabular}{|c|c|c|c|c|}
\hline 1350 & 1360 & 1370 & 1380 & 1390 \\
\hline
\end{tabular}

A. flavus I IRGQLIGKGTYGRVYLGMNADNGEVLAVKQVEINPRIAGQDKDKMKDMVAAM

A. oryzae I IRGQLIGKGTYGRVYLGMNADNGEVLAVKQVEINPRIAGQDKDKMKDMVAAM

A. fumigatus I IRGQLIGKGTYGRVYLGINADNGEVLAVKQVEINPRLAGQDTDRVKEMVAAM

Pneumocystis carinii WIKGALI GSGSF GSVFLGMNALSGELMAVKQVEIP-SIDIQGCKRKRAMLDAL

S. cerevisiae WMKGEMIGKGSFGAVYLCLNVTTGEMMAVKQVEVPKYSSQ- -NEAILSTVEAL

B

$1,1,1,1,1,1,1,1,1,1,1$

WT GGCTGTT $\nexists$ ACAGGTGG $\nexists \nexists A T C A A T$

K1330RGGCTGTTAGGCAGGTGG $\nexists \nexists A T C A A T$

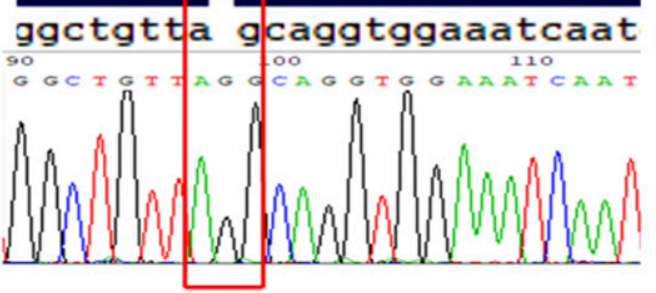

C

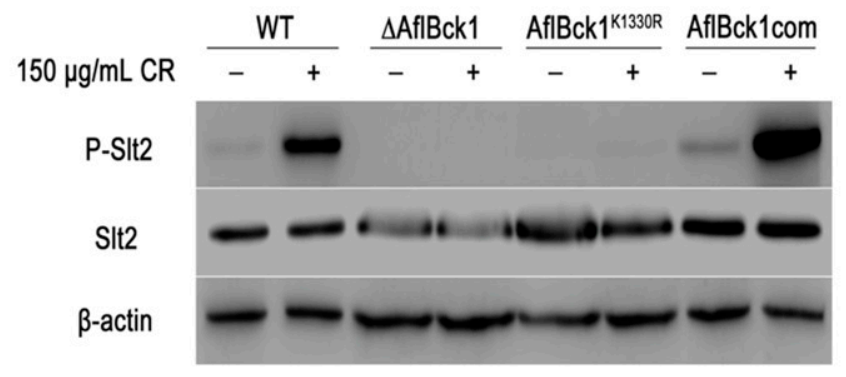

Fig. 9. Construction and confirmation of $A f l B c k 1^{K 1330 R}$ strains. A, Alignment of partial sequence of Bck1 homologs. Orange arrow indicates the conserved lysine residue. B, Sequencing confirmation of $A f l B c k 1^{K 1330 R}$ strains. C, Western blot confirmation of $A f l B c k 1^{K 1330 R}$ strains. Proteins were extracted from wild type (WT), $\triangle A f l B c k l, A f l B c k I^{K 1330 R}$, and AflBck1 com strains grown in yeast extract-sucrose liquid medium for $12 \mathrm{~h}$ at $37^{\circ} \mathrm{C}$ and treated with or without Congo red for 15 min before harvesting. Phosphorylated Slt2 (P-Slt2), Slt2, and $\beta$-actin (as loading control) were detected with antiphospho-p44/42, anti-Slt2, and anti- $\beta$-actin antibodies, respectively. 
$\mathrm{Thr}^{368}$ and $\mathrm{Thr}^{374}$ of AflMkk2 in $\triangle A$ flBckl mutant with Asp (Fig. 10A) (Yin et al. 2016). As shown in Figure 10B, the phosphorylated Slt2 reappeared in both $\triangle A f l B c k 1 / M k k 2^{D D}$ mutants, although the intensity of Slt2 phosphorylation detected in the $\triangle A f l B c k 1 / M k k 2^{D D}$ mutants was not as strong as that in WT. On a similar note, resistance to Congo red was partially recovered in the $\triangle A f l B c k l / M k k 2^{D D}$ strains, in comparison with the $\triangle A f l B c k l$ strain (Fig. 10C and D). Taken together, these results indicate that AflBck1 is epistatic to AflMkk2 in the Slt2-MAPK pathway.

To a better understanding of $A f l B c k 1$ epistatic to AflMkk2, we examined the phenotypic changes in $\Delta A f l M k k 2$ mutants. By applying a similar approach to disrupt $A f l B c k l$ gene, we obtained the AflMkk2 deletion and complementary strains (Supplementary Fig. S2). The $\Delta A f l M k k 2$ mutants showed a grievous fault in colony growth with respect to the WT and AflMkk2 complemented strains (Fig. 11A). The $\Delta A f l M k k 2$ mutants displayed shriveled colony margins, which was consistent with the results from the $\triangle A f l B c k 1$ mutant. Further, we found that the ability to produce conidia in the $\triangle A f l M k k 2$ mutants was destroyed, in contrast to the conidiation of the WT and AflMkk2 complemented strains (Fig. 11B). We also compared the ability to produce sclerotia of $\Delta A f l M k k 2$ mutants with that of the WT and AflMkk2 complemented strains. As showed in Figure 11C, the sclerotia formation in $\Delta A f l M k k 2$ mutants was completely abolished, while the WT and AflMkk2 complemented strains had the normal capacity to produce sclerotia. By contrast, the production of aflatoxin was upregulated in $\Delta A f l M k k 2$ mutants (Fig. 11D). All above results also supported that AflBck1 was genetic epistasis of AflMkk2 in Slt2-MAPK pathway.

\section{The PRR of AflBckl influences conidia} and sclerotia formation.

As results from sequence analysis in Figure 1A, we found that all selected filamentous fungi harbored a PRR at the $\mathrm{N}$ terminus of Bck1 protein. As far as we are aware, the function of this structure has not been explored in Bck1 homologs of filamentous fungi. In a manner analogous to the AflBck1 knockout, we constructed a strain omitting the PRR of AflBck1 and checked whether PRR was of functional importance for AflBck1. As can be seen in Supplementary Fig. S3, $A f l B c k 1^{\triangle P R R}$ mutant displayed a WT phenotype in growth, response to stress, and aflatoxin biosynthesis. To our surprise, the AflBck $1^{\triangle P R R}$ mutant showed an increase in conidia production but an abolition in sclerotia formation as compared with the WT strain (Fig. 12). These results point to the PRR of AflBck1 influencing conidia and sclerotia formation in A. flavus.

\section{DISCUSSION}

MAPK cascades are conserved signal pathways that transduce signals from the cell surface to the nucleus. This allows them to participate in numerous biological processes, such as development, response to environmental stimuli, and pathogenesis (Zhao et al. 2007). In a previous study, we have investigated two components of the Hog1-MAPK pathway and found that both kinases functioned in morphogenesis differentiation, aflatoxin biosynthesis, and plant infection in A. flavus (Tumukunde et al. 2019; Yuan et al. 2018). This arouses our interest in the biological functions of Slt2-MAPK. For this purpose, we disrupted AflBck1, the MAPKKK in the Slt2MAPK pathway from $A$. flavus, using a split-marker strategy.

Sit2-MAPK pathway is believed to be essential for the maintenance of CWI in fungi (Xu 2000). For example, the $\Delta$ Slt2 mutant displays serious defects in response to cell wall-disturbing agents in various fungi, such as Alternaria alternata (Yago et al. 2011), Fusarium graminearum (Hou et al. 2002), A. fumigatus (Valiante et al. 2008), Cryphonectria parasitica (So et al. 2017), and Trichoderma reesei (Wang et al.
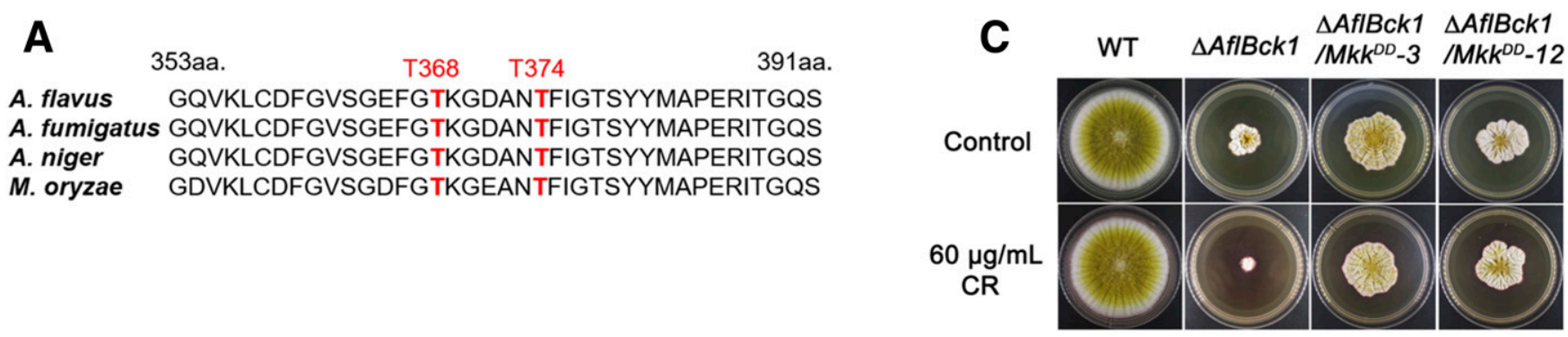

B

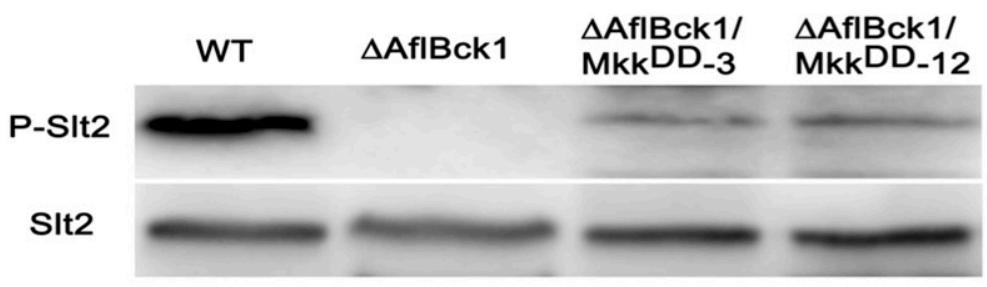

D

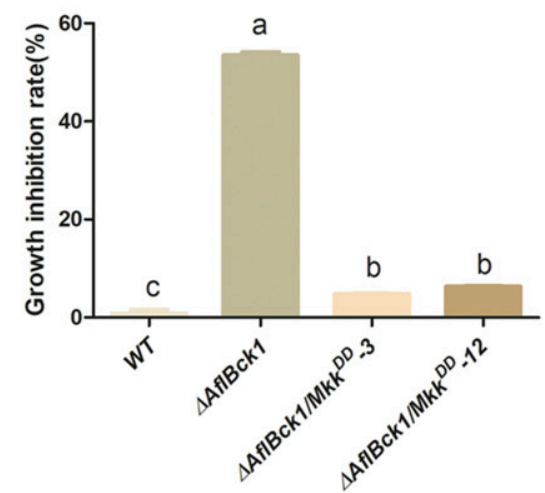

Fig. 10. Rescue assay of $\triangle A f l B c k 1$ strain. A, Alignment of the phosphorylation consensus motif of Mkk2 homologs. The phosphorylated residues of Mkk2 were written in red. B, Western blot analysis of Slt2 phosphorylation. Proteins were extracted from wild type (WT), $\Delta A f l B c k 1, \Delta A f l B c k 1 / M k k 2^{D D}-3$, and $\triangle A f l B c k 1 / M k k 2^{D D}-12$ strains grown in yeast extract-sucrose (YES) liquid medium for $12 \mathrm{~h}$ at $37^{\circ} \mathrm{C}$ and treated with or without Congo red (CR) for 15 min before harvesting. Phosphorylated Slt2 (P-Slt2) and Slt2 (as loading control) were detected with antiphospho-p44/42 and anti-Slt2 antibodies, respectively. C, Colony morphology of the WT, $\triangle A f l B c k 1, \triangle A f l B c k 1 / M k k 2^{D D}-3$, and $\triangle A f l B c k 1 / M k k 2^{D D}-12$ strains grown on YES solid media supplemented with or without CR at $37^{\circ} \mathrm{C}$ for 3 days. $\triangle A f l B c k 1 / M k k 2^{D D}-3$ and $\triangle A f l B c k 1 / M k k 2^{D D}-12$ are two clones isolated from the same transformation. $\mathbf{D}$, The inhibition rate of radial growth of the strains shown in C. Different letters above the bars represent significant difference $(P<0.001)$. 
2014). As expected, deletion of Bckl from A. flavus leads to hypersensitivity to cell-wall stress, which is similar to the orthologs in other pathogenic fungi including M. oryzae (Jeon et al. 2008), C. parasitica (Kim et al. 2016), Coniothyrium minitans (Zeng et al. 2012), and Fusarium verticillioides (Zhang et al. 2015). Peculiarly, lack of Bckl does not result in higher sensitivity to cell wall-damaging chemicals in the milk yeast Kluyveromyces lactis (Jacoby et al. 1999). Yet, heterologous complementation of $K$. lactis Bckl into a $S$. cerevisiae $B c k 1$ null mutant restored resistance to caffeine, a cell walldamaging agent. Similarly, $P$. carinii Bckl salvaged the CWI defect in the $S$. cerevisiae $\Delta B c k 1$ mutant (Thomas et al. 2003). These studies imply that the function of Bck1 in CWI is conserved among fungi.

The cell wall is essential for cell division and morphological development in fungi. Thus, it is not surprising that the $\triangle A f l B c k 1$ mutant exhibited severely retarded growth compared with WT and complemented strain. This outcome is in line with the mutant characteristics of Bckl orthologs, including C. parasitica (Kim et al. 2016), F. verticillioides (Zhang et al. 2015), and A. fumigatus (Valiante et al. 2008). Interestingly, we noticed that the $\triangle A f l B c k l$ mutant formed swollen structures at the tip of hyphae, which is also observed in the Bckl deletion mutant of $F$. verticillioides (Zhang et al. 2015). In A. fumigatus, Valiante and coworkers (2008) found that the $\Delta B c k 1$ mutant had excessive branching hyphae in comparison with WT. Most interestingly, mutation in $C$. parasitica $B c k 1$ resulted in a sporadic sectorization colony (So et al. 2018). In addition, the mycelia of $C$. parasitica $\Delta B c k 1$ mutant showed an impaired hydrophobicity (So and Kim 2017), which is in agreement with our findings. Although the Bckl orthologs of M. oryzae and Coniothyrium minitans are not required for hyphal growth, hyphal autolysis was sharply enhanced in the $\Delta B c k 1$ mutants (Jeon et al. 2008; Zeng et al. 2012). Maybe this lysis contributes to the drastic decrease in conidiation (Jeon et al. 2008).
However, this autolysis phenotype was not observed in A. flavus $\Delta B c k 1$ mutant, indicating a specie-specific role of Bck1 in morphological development.

According to previous publications, aflatoxin biosynthesis is highly interconnected with the oxidative status of A. flavus (Zhang et al. 2016, 2018). In our data, we observed that loss of $A f l B c k 1$ improved resistance to hydrogen peroxide. The upregulated expression of oxidative-stress defense genes in the $\triangle A f l B c k 1$ mutant provides compelling evidence. However, different behavior was observed in the $F$. verticillioides $\Delta B c k 1$ mutant under oxidative stresses (Zhang et al. 2015). In yeast, significant progress has been made in the understanding of the role of Bck1 in response to hydrogen peroxide. Transcriptional repressor cyclin $\mathrm{C}$ regulates many stress response genes in yeast. Under low oxidative stress, activated Bck1 induces cyclin $\mathrm{C}$ translocation and degradation, whereas Bck1 is not essential to destruction of cyclin $\mathrm{C}$ under high stress (Jin et al. 2015). Many studies have revealed that aflatoxin generation can alleviate damage by ROS accumulation (Kenne et al. 2018; Roze et al. 2015). We observed here that the $\Delta A f l B c k 1$ mutant displayed an augmented aflatoxin production, which seems to provide an answer to a better tolerance to $\mathrm{H}_{2} \mathrm{O}_{2}$ of the mutant. However, the exact mechanism by which A. flavus Bck1 negatively controls oxidative response remains to be further investigated.

In A. flavus, aflatoxin is the major culprit that threatens animal and human health. Considering this, it is necessary to survey whether $A f l B c k 1$ relates to aflatoxin production. Here, we observed that disruption of $A f l B c k 1$ resulted in increased aflatoxin generation in YES broth. This result completely agrees with aflatoxigenic characteristics exhibited by the A. flavus $\triangle$ sakA/hogA mutant, which also shows increased aflatoxin generation (Tumukunde et al. 2019). This consistency may be explained by similar regulation mechanisms of aflatoxin biosynthesis between Slt2-MAPK and Hog1-MAPK.
A

WT

$\Delta m k k 2$

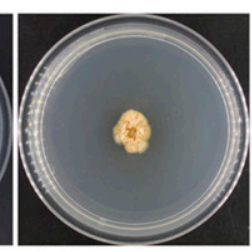

PDA

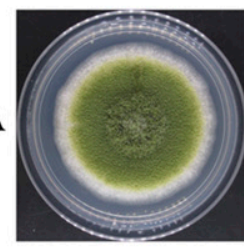

B

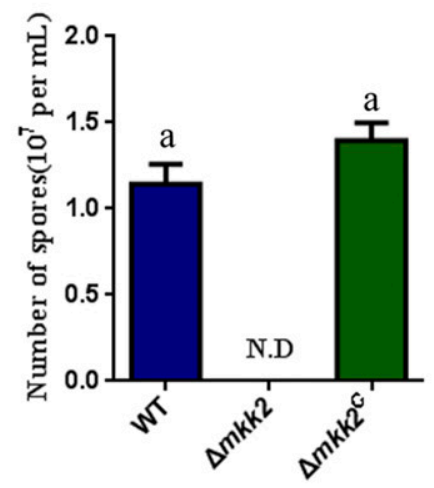

$\Delta m k k 2^{\mathrm{C}}$

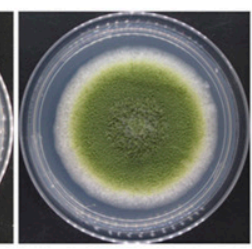

C

Before washed

After washed

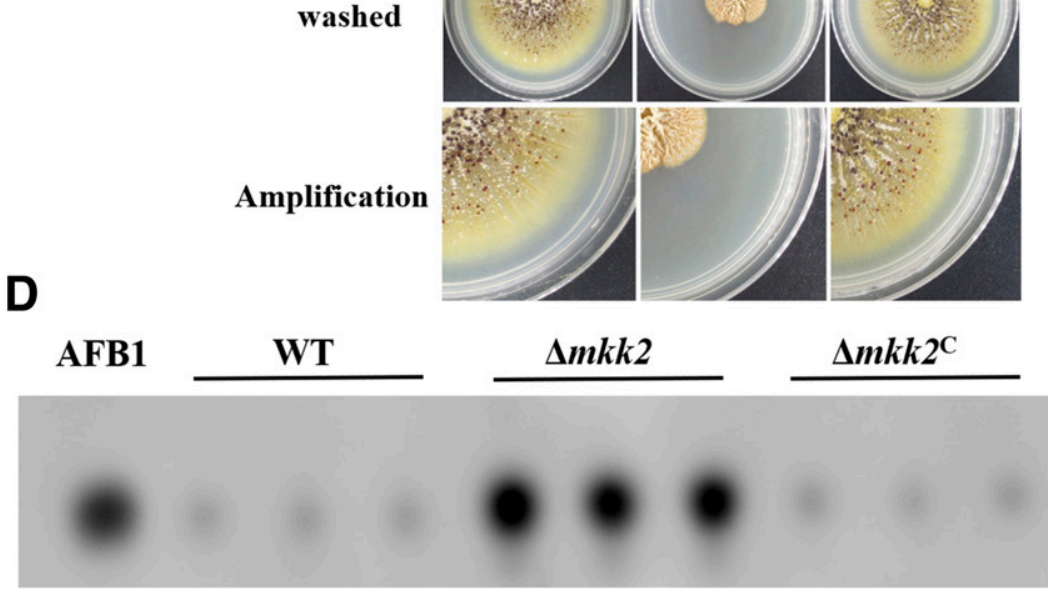

Fig. 11. Phenotypes of $\triangle A f l M k k 2$ mutants. A, Colony morphology of wild type (WT), $\Delta A f l M k k 2$, and AflMkk2 complemented strains, on potato dextrose agar (PDA) solid media after 4 days of inoculation. B, Conidia production collected from samples shown in A. C, Sclerotial formation of different strains on Wickerham solid media after growth for 7 days at $37^{\circ} \mathrm{C}$. D, Thin-layer chromatography measurements of aflatoxin B1 (AFB1). All strains were cultured in yeast extract-sucrose liquid medium for 7 days at $29^{\circ} \mathrm{C}$. ND $=$ not detectable. 
Like aflatoxin produced by A. flavus, riboflavin is a product of the secondary metabolism in Ashbya gossypii. Earlier study showed that the $\Delta B c k 1$ mutant of Ashbya gossypii displayed a strong increase in riboflavin biosynthesis (Lengeler et al. 2013). A similar result was found when A. fumigatus lacked Bckl, which produced more pyomelanin than the WT (Valiante et al. 2008). However, loss of $B c k l$ has an inhibitory effect on mycotoxin fumonisin B1 production in F. verticillioides (Zhang et al. 2015). These results might reflect absolutely different roles played by Bck1 in specific secondary metabolism. Unfortunately, the exact role of Bck1 in the regulation of secondary metabolism is still an unsolved question.

In addition to producing aflatoxin, A. flavus is capable of colonizing numerous crop seeds. Pathogenicity assays showed that the deletion of AflBckl dramatically ablated the ability to infect plant hosts. A similar phenomenon on attenuated pathogenicity of $\triangle B c k l$ mutant has also been reported in F. verticillioides (Zhang et al. 2015), C. parasitica (Kim et al. 2016), and M. oryzae (Jeon et al. 2008). In M. oryzae, deletion of $B c k l$ reduces the turgor pressure of the infection structure, weakening the ability to penetrate plant tissues (Jeon et al. 2008). The Bck1 homolog in $F$. verticillioides regulates the expression of catalase and peroxidase, which prevents fungi from oxidative damage by the host (Zhang et al. 2015). The fungal cell wall acts as the first line of defense against host challenges, whose integrity is extremely important for fungal infection. As depicted in Figure 5, lack of AflBckl lends to augmented sensitivity to several cell wall-damaging compounds, implicating that $A f l B c k l$ abrogates the ability to cope with the stresses during infection. Again, the deficiencies in growth and development are also fatal for $\triangle A f l B c k l$ colonization. We observed here that $\mathrm{AFB}_{1}$ production of the $\triangle A f l B c k 1$ mutant on peanuts was much more than WT and AflBcklcom strains. In fact, similar results were obtained from phosphatase CDC14 loss mutant, which displayed impaired colonization but enhanced aflatoxin generation on seeds (Yang et al. 2018). These results seem to implicate no direct connection between pathogenicity and AFB1 production. However, all presently
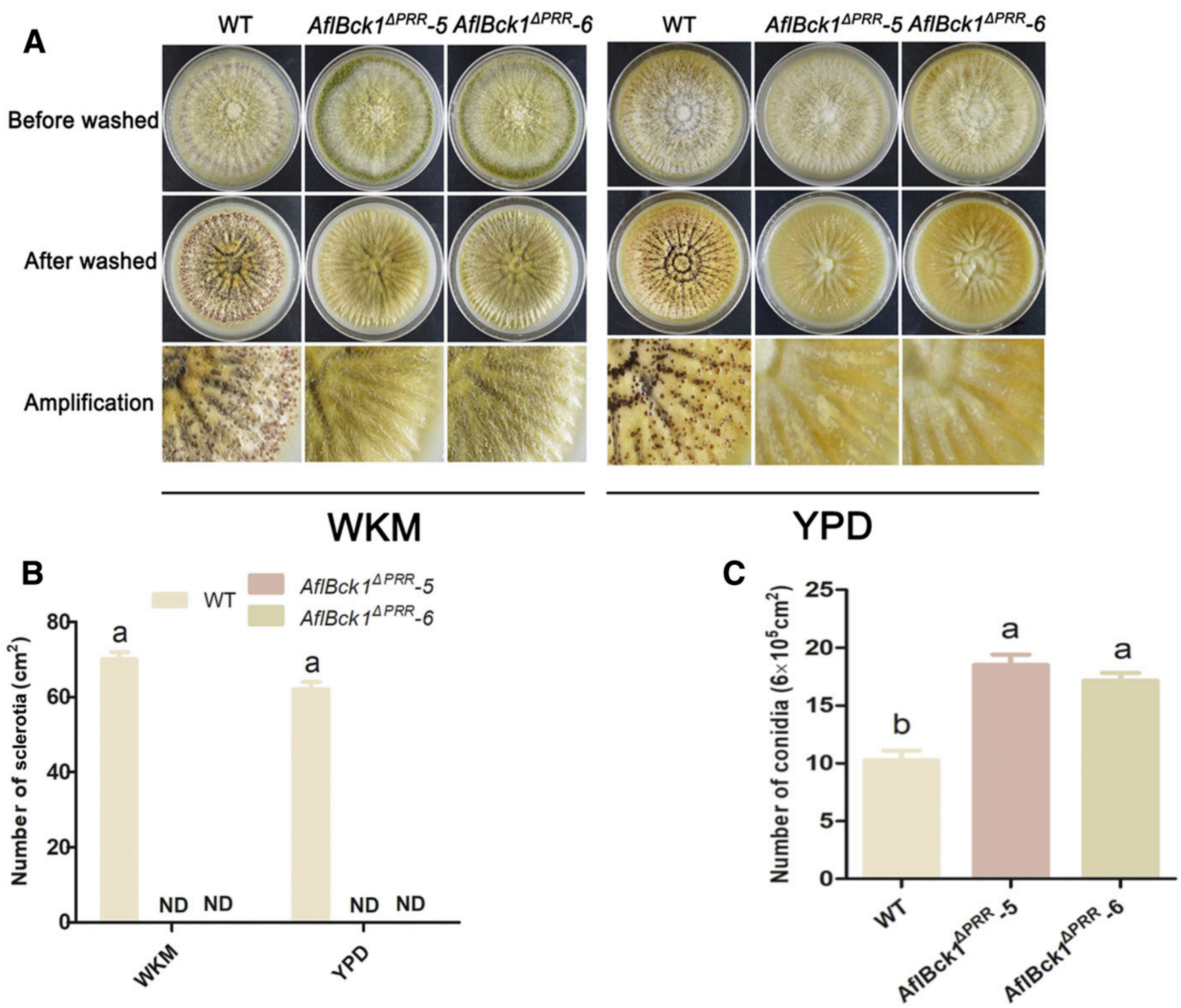

Fig. 12. Defects of Aspergillus flavus strains lacking the proline-rich region of AflBck1. A, Sclerotial formation of the wild type (WT), $\triangle A f l B c k 1^{\triangle P R R}-5$, and $\triangle A$ flBck $1^{\triangle P R R}-6$ strains on Wickerham medium (WKM) and yeast extract peptone dextrose solid media after growth for 7 days at $37^{\circ} \mathrm{C}$. B, Quantitative analysis of the sclerotia shown in A. C, Conidia production of the WT, $\triangle A f l B c k 1^{\triangle P R R}-5$, and $\triangle A f l B c k 1^{\triangle P R R}-6$ strains on yeast extract-sucrose solid media at $37^{\circ} \mathrm{C}$ for 4 days. $\triangle A f l B c k 1^{\Delta P R R}-5$ and $\triangle A f l B c k 1^{\Delta P R R}-6$ are two clones isolated from the same transformation. ND = not detectable. 
available data indicate that a correlation indeed exists between AflBckl and pathogenesis in A. flavus.

Another interesting finding of this work is the critical function of a PRR of AflBck1 in conidia and sclerotia formation. As reported previously, the PRR is frequently found in eukaryotic proteins, which plays versatile roles in protein function (Williamson 1994). In one example, the PRR in huntingtin protein determines toxic properties of this protein (Dehay and Bertolotti 2006). In another example, the PRR of human p53 protein is necessary for promoting apoptosis of tumor cells (Baptiste et al. 2002). In this study, we have presented evidence for the first time that the PRR of AflBck1 is involved in conidia and sclerotia formation. Although the mechanisms involved are currently unknown, many elegant studies have demonstrated that PRR mainly contributes the interaction of signaling proteins with their ligands (Kay et al. 2000). Deletion of the PRR of Fbx7 disrupts the combination of Fbx7 and HURP (Hsu et al. 2004). When NoxA1 lacks the N-terminal PRR, Tks proteins cannot bind NoxA1 and mediate Nox1-dependent ROS generation (Gianni et al. 2011). Thus, we infer that the PRR of AflBck1 may influence interaction between AflBck1 and reproductionrelated proteins. Future studies will be necessary to clarify the underlying mechanisms for PRR of AflBck1 regulating $A$. flavus reproduction.

In summary, we characterized a CWI-related MAPKKK, which exhibited a pivotal function in the growth, development, aflatoxin biosynthesis, and pathogenesis in A. flavus. When the activation site of this kinase was mutated, the phosphorylation of MAPK was almost abolished. In addition, we have presented evidence, for the first time, that the PRR of Bck1 plays a significant role in conidia and sclerotia formation. This work further underlined the functional importance of MAPK pathway in A. flavus, suggesting the possibility of developing novel fungicides to control $A$. flavus contamination.

\section{MATERIALS AND METHODS}

\section{Strains and culture conditions.}

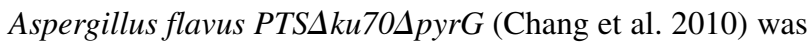
used as an original strain for gene knockout and PTS $\Delta$ ku70DpyrG::AfpyrG was used as the WT strain. All A. flavus strains used in this study are listed in Supplementary Table S1. Growth and development experiments were performed as described in the previous studies (Zhang et al. 2016, 2018).

\section{Sequence analysis and phylogenetic tree construction.}

The Bck1 protein sequences of A. flavus, S. cerevisiae, Candida albicans, $M$. oryzae, A. oryzae, A. nidulans, A. fumigatus, $A$. niger, and $N$. crassa were downloaded from National Center for Biotechnology Information resources. The Bck1 protein domain was identified by SMART and ScanProsite and was drawn by DOG 2.0 software. The phylogenetic tree was constructed, by clustalw alignment comparison of MEGA7.0 software, using the neighbor-joining method.

\section{Construction of the gene knockout and complementation strains.}

To construct gene knockout strains, a homologous recombination method was used as described previously (Zhang et al. 2016). The primers used in this study are listed in Supplementary Table S2. Positive transformants were verified by diagnostic PCR and Southern blot (North2SouthChemiluminescent Hybridization and Detection Kit, Thermo scientific). For constructing the complementation strain, gene-coding sequence and its native promoter were cloned into the Aspergillus chromosome integrating pPTRI vector (Takara), and then, the confirmed vectors were used to transform $\triangle A f l B c k 1$ protoplasts of A. flavus. PCR and RT-PCR were used to confirm the positive transformants.

\section{Stress assays.}

For stress assays, $10^{4}$ conidia were inoculated onto the center of YES agar medium plates supplemented with the following agents: oxidative stress agent hydrogen peroxide $\left(\mathrm{H}_{2} \mathrm{O}_{2}, 3,6,9\right.$, or $12 \mathrm{mM})$, cell-wall stress agents Calcofluor white $(8 \mu \mathrm{g} / \mathrm{ml})$ and Congo red $(60 \mu \mathrm{g} / \mathrm{ml})$, cell-membrane stress agent sodium dodecyl sulfate $(45 \mu \mathrm{g} / \mathrm{ml})$. Each plate was incubated at $37^{\circ} \mathrm{C}$ for 4 days under dark conditions and colony diameters were measured daily. The experiment was conducted with technical triplicates and were repeated three times.

\section{RNA extraction and quantitative RT-PCR.}

The mycelia of WT and all mutant strains were harvested at growth stages (48 and $72 \mathrm{~h}$, incubated on YES or WKM). Total RNA extraction and a quantitative real-time PCR assay were performed according to the previously reported protocols (Zhang et al. 2016). In the quantitative real-time PCR, actin gene was used as the endogenous reference gene, and other primers of target genes are listed in Supplementary Table S3. The relative transcript level of each gene was calculated by the $2^{-\Delta \Delta \mathrm{Ct}}$ method (Livak and Schmittgen 2001). All experiments were carried out three times.

\section{Determination of aflatoxin production.}

WT, $\triangle A f l B c k l, A f l B c k 1^{K 1330 R}$, and AflBcklcom strains $\left(10^{6}\right.$ spores) were incubated in $15 \mathrm{ml}$ of YES liquid medium in the dark at $29^{\circ} \mathrm{C}$ for 7 days. Chloroform was used to leach aflatoxin, and the extraction method was followed as previously described (Zhang et al. 2018). TLC was used to analyze aflatoxin, and results were shown under the irradiation of $365 \mathrm{~nm}$ ultraviolet rays. Then aflatoxin production was quantified by Gene Tools software.

\section{Seed infections.}

The peanut infection experiment of various strains was carried out according to previously reported steps (Zhang et al. 2018). Briefly, peanut cotyledons were sterilized with $0.05 \%$ sodium hypochlorite and $75 \%$ anhydrous ethanol; $30 \mathrm{ml}$ of sterile water and $10^{6}$ spores were added to every 50 peanut cotyledons and were placed in a $29^{\circ} \mathrm{C}$ shaker at $80 \mathrm{rpm}$ for $1 \mathrm{~h}$. Peanuts were then cultured in a $29^{\circ} \mathrm{C}$ incubator for 7 days. The peanut cotyledons were then harvested in 50-ml centrifuge tubes and $10 \mathrm{ml}$ of sterile water with $0.05 \%$ Tween-20 was added to wash conidia. The number of conidia was counted using a hemocytometer and microscope, and aflatoxin was extracted as described above. Each experiment was repeated three times.

\section{Generation of AflBck1 ${ }^{\mathrm{K1330R}}, \Delta \mathrm{AflBck} 1 / \mathrm{Mkk2} 2^{\mathrm{DD}}$, and AflBck1 $^{\Delta \text { PRR }}$ strains.}

To generate an $A f l B c k 1^{K 1330 R}$ strain, a 1,561-bp fragment of the AflBckl gene including the mutation site $(1,330$, replacing lysine with arginine), a 1,476-bp downstream fragment of AflBckl gene, and the A. fumigatus pyrG cassette were fused and transformed into the original strain (Szewczyk et al. 2007). The $\triangle A f l B c k 1 / M k k 2^{D D}$ mutant bearing residues T368 and T374 to Asp was generated using an analogous strategy, but a pyrithiamine resistance gene derived from $p P T R I$ vector served as a selectable marker and the $\triangle A f l B c k l$ mutant as a parental strain. For the generation of an $A f l B c k 1^{\triangle P R R}$ strain, the coding sequence of $A f l B c k l$ containing amino acids 1 to 10 was fused to the AflBckl coding sequence including amino acids 100 to 1,592 , with the application of homologous recombination 
method as mentioned above (Szewczyk et al. 2007). All positive constructs were verified by PCR and sequencing. The primers used in this section are listed in Supplementary Table S4.

\section{Western blot analysis.}

Each strain $\left(5 \times 10^{6}\right.$ spores $)$ was inoculated into $50 \mathrm{ml}$ of YES liquid medium, respectively, and was shaken at $180 \mathrm{rpm}$ for 2 days (or another $15 \mathrm{~min}$ with $150 \mu \mathrm{g}$ of Congo red per milliliter) in a $37^{\circ} \mathrm{C}$ shaker. Protein preparation and Western blot experiments were performed as described previously (Lan et al. 2019). The antibodies (Cell Signaling Technology) against target proteins were added and were incubated with a polyvinylidene diflouride membrane, and chemiluminescence was detected using the Gene Imaging System (Syngene).

\section{ACKNOWLEDGMENTS}

We especially thank P. K. Chang (Southern Regional Research Center, United States Department of Agriculture, New Orleans, LA, U.S.A) for his kindness in providing the strains.

\section{AUTHOR-RECOMMENDED INTERNET RESOURCES}

SMART: http://smart.embl-heidelberg.de

ScanProsite: https://prosite.expasy.org/scanprosite

\section{LITERATURE CITED}

Baptiste, N., Friedlander, P., Chen, X., and Prives, C. 2002. The proline-rich domain of p53 is required for cooperation with anti-neoplastic agents to promote apoptosis of tumor cells. Oncogene 21:9-21.

Bojović-Cvetić, D., and Vujičić, R. 1974. Ultrastructure of conidiophores in Aspergillus flavus. Trans. Br. Mycol. Soc. 63:131-135, IN60-IN120.

Cary, J. W., Harris-Coward, P. Y., Ehrlich, K. C., Mack, B. M., Kale, S. P., Larey, C., and Calvo, A. M. 2012. NsdC and NsdD affect Aspergillus flavus morphogenesis and aflatoxin production. Eukaryot. Cell 11: 1104-1111.

Chang, P.-K., Scharfenstein, L. L., Wei, Q., and Bhatnagar, D. 2010. Development and refinement of a high-efficiency gene-targeting system for Aspergillus flavus. J. Microbiol. Methods 81:240-246.

Dehay, B., and Bertolotti, A. 2006. Critical role of the proline-rich region in huntingtin for aggregation and cytotoxicity in yeast. J. Biol. Chem. 281: $35608-35615$.

Georgianna, D. R., and Payne, G. A. 2009. Genetic regulation of aflatoxin biosynthesis: From gene to genome. Fungal Genet. Biol. 46:113-125.

Gianni, D., DerMardirossian, C., and Bokoch, G. M. 2011. Direct interaction between Tks proteins and the $\mathrm{N}$-terminal proline-rich region (PRR) of NoxA1 mediates Nox1-dependent ROS generation. Eur. J. Cell Biol. 90:164-171.

Hedayati, M. T., Pasqualotto, A. C., Warn, P. A., Bowyer, P., and Denning, D. W. 2007. Aspergillus flavus: Human pathogen, allergen and mycotoxin producer. Microbiology 153:1677-1692.

Hou, Z., Xue, C., Peng, Y., Katan, T., Kistler, H. C., and Xu, J.-R. 2002. A mitogen-activated protein kinase gene $(M G V 1)$ in Fusarium graminearum is required for female fertility, heterokaryon formation, and plant infection. Mol. Plant-Microbe Interact. 15:1119-1127.

Hsu, J. M., Lee, Y. C., Yu, C. T., and Huang, C. Y. 2004. Fbx7 functions in the SCF complex regulating Cdk1-cyclin B-phosphorylated hepatoma up-regulated protein (HURP) proteolysis by a proline-rich region. J. Biol. Chem. 279:32592-32602.

Jacoby, J. J., Kirchrath, L., Gengenbacher, U., and Heinisch, J. J. 1999. Characterization of $K L B C K 1$, encoding a MAP kinase kinase kinase of Kluyveromyces lactis. J. Mol. Biol. 288:337-352.

Jeon, J., Goh, J., Yoo, S., Chi, M.-H., Choi, J., Rho, H.-S., Park, J., Han, S.-S., Kim, B. R., Park, S.-Y., Kim, S., and Lee, Y. H. 2008. A putative MAP kinase kinase kinase, MCK1, is required for cell wall integrity and pathogenicity of the rice blast fungus, Magnaporthe oryzae. Mol. PlantMicrobe Interact. 21:525-534.

Jiang, C., Zhang, X., Liu, H., and Xu, J.-R. 2018. Mitogen-activated protein kinase signaling in plant pathogenic fungi. PLoS Pathog. 14: e1006875.

Jin, C., Kim, S. K., Willis, S. D., and Cooper, K. F. 2015. The MAPKKKs Ste11 and Bck1 jointly transduce the high oxidative stress signal through the cell wall integrity MAP kinase pathway. Microb. Cell 2:329-342.
Kay, B. K., Williamson, M. P., and Sudol, M. 2000. The importance of being proline: The interaction of proline-rich motifs in signaling proteins with their cognate domains. FASEB J. 14:231-241.

Kenne, G. J., Gummadidala, P. M., Omebeyinje, M. H., Mondal, A. M., Bett, D. K., McFadden, S., Bromfield, S., Banaszek, N., Velez-Martinez, M., Mitra, C., Mikell, I., Chatterjee, S., Wee, J., and Chanda, A. 2018. Activation of aflatoxin biosynthesis alleviates total ROS in Aspergillus parasiticus. Toxins (Basel) 10:57.

Kim, J.-M., Lee, J.-G., Yun, S.-H., So, K.-K., Ko, Y.-H., Kim, Y. H., Park, S.-M., and Kim, D.-H. 2016. A Mutant of the Bck1 homolog from Cryphonectria parasitica resulted in sectorization with an impaired pathogenicity. Mol. Plant-Microbe Interact. 29:268-276.

Klich, M. A. 2007. Aspergillus flavus: The major producer of aflatoxin. Mol. Plant Pathol. 8:713-722.

Krijgsheld, P., Bleichrodt, R., van Veluw, G. J., Wang, F., Müller, W. H., Dijksterhuis, J., and Wösten, H. A. B. 2013. Development in Aspergillus. Stud. Mycol. 74:1-29.

Lan, H., Wu, L., Sun, R., Keller, N. P., Yang, K., Ye, L., He, S., Zhang, F., and Wang, S. 2019. The HosA histone deacetylase regulates aflatoxin biosynthesis through direct regulation of aflatoxin cluster genes. Mol. Plant-Microbe Interact. 32:1210-1228

Lengeler, K. B., Wasserstrom, L., Walther, A., and Wendland, J. 2013. Analysis of the cell wall integrity pathway of Ashbya gossypii. Microbiol. Res. 168:607-614.

Levin, D. E. 2005. Cell wall integrity signaling in Saccharomyces cerevisiae. Microbiol. Mol. Biol. Rev. 69:262-291.

Livak, K. J., and Schmittgen, T. D. 2001. Analysis of relative gene expression data using real-time quantitative PCR and the $2^{-\Delta \Lambda \mathrm{C}(\mathrm{T}}$ method. Methods 25:402-408.

Mitchell, N. J., Bowers, E., Hurburgh, C., and Wu, F. 2016. Potential economic losses to the US corn industry from aflatoxin contamination. Food Addit. Contam. Part A Chem. Anal. Control Expo. Risk Assess. 33: 540-550.

Molina, M., Cid, V. J., and Martín, H. 2010. Fine regulation of Saccharomyces cerevisiae MAPK pathways by post-translational modifications. Yeast 27:503-511.

Moye-Rowley, W. S. 2003. Regulation of the transcriptional response to oxidative stress in fungi: Similarities and differences. Eukaryot. Cell 2: 381-389.

Nie, X., Li, B., and Wang, S. 2018. Epigenetic and posttranslational modifications in regulating the biology of Aspergillus species. Adv Appl. Microbiol. 105:191-226.

Roze, L. V., Laivenieks, M., Hong, S.-Y., Wee, J., Wong, S.-S., Vanos, B., Awad, D., Ehrlich, K. C., and Linz, J. E. 2015. Aflatoxin biosynthesis is a novel source of reactive oxygen species-A potential redox signal to initiate resistance to oxidative stress? Toxins (Basel) 7:1411-1430.

So, K.-K., and Kim, D.-H. 2017. Role of MAPK signaling pathways in regulating the hydrophobin cryparin in the chestnut blight fungus Cryphonectria parasitica. Mycobiology 45:362-369.

So, K.-K., Ko, Y.-H., Chun, J., Bal, J., Jeon, J., Kim, J.-M., Choi, J., Lee, Y.-H., Huh, J. H., and Kim, D.-H. 2018. Global DNA methylation in the chestnut blight fungus Cryphonectria parasitica and genome-wide changes in DNA methylation accompanied with sectorization. Front. Plant Sci. 9:103.

So, K.-K., Ko, Y.-H., Chun, J., Kim, J.-M., and Kim, D.-H. 2017. Mutation of the Slt2 ortholog from Cryphonectria parasitica results in abnormal cell wall integrity and sectorization with impaired pathogenicity. Sci. Rep. 7:9038.

Szewczyk, E., Nayak, T., Oakley, C. E., Edgerton, H., Xiong, Y., TaheriTalesh, N., Osmani, S. A., and Oakley, B. R. 2007. Fusion PCR and gene targeting in Aspergillus nidulans. Nat. Protoc. 1:3111-3120.

Talbot, N. J. 1997. Fungal biology: Growing into the air. Curr. Biol. 7 : R78-R81.

Thomas, C. F., Jr., Vohra, P. K., Park, J. G., Puri, V., Limper, A. H., and Kottom, T. J. 2003. Pneumocystis carinii BCK1 functions in a mitogenactivated protein kinase cascade regulating fungal cell-wall assembly FEBS Lett. 548:59-68

Tumukunde, E., Li, D., Qin, L., Li, Y., Shen, J., Wang, S., and Yuan, J. 2019. Osmotic-adaptation response of sakA/hogA gene to aflatoxin biosynthesis, morphology development and pathogenicity in Aspergillus flavus. Toxins (Basel) 11:41

Valiante, V., Heinekamp, T., Jain, R., Härtl, A., and Brakhage, A. A. 2008. The mitogen-activated protein kinase MpkA of Aspergillus fumigatus regulates cell wall signaling and oxidative stress response. Fungal Genet. Biol. 45:618-627.

Wang, M., Dong, Y., Zhao, Q., Wang, F., Liu, K., Jiang, B., and Fang, X. 2014. Identification of the role of a MAP kinase Tmk2 in Hypocred jecorina (Trichoderma reesei). Sci. Rep. 4:6732. 
Widmann, C., Gibson, S., Jarpe, M. B., and Johnson, G. L. 1999. Mitogenactivated protein kinase: Conservation of a three-kinase module from yeast to human. Physiol. Rev. 79:143-180.

Williamson, M. P. 1994. The structure and function of proline-rich regions in proteins. Biochem. J. 297:249-260.

$\mathrm{Xu}$, J.-R. 2000. Map kinases in fungal pathogens. Fungal Genet. Biol. 31: 137-152.

Yago, J. I., Lin, C. H., and Chung, K. R. 2011. The SLT2 mitogen-activated protein kinase-mediated signalling pathway governs conidiation, morphogenesis, fungal virulence and production of toxin and melanin in the tangerine pathotype of Alternaria alternata. Mol. Plant Pathol. 12: 653-665.

Yang, G., Hu, Y., Fasoyin, O. E., Yue, Y., Chen, L., Qiu, Y., Wang, X., Zhuang, Z., and Wang, S. 2018. The Aspergillus flavus phosphatase CDC14 regulates development, aflatoxin biosynthesis and pathogenicity. Front. Cell. Infect. Microbiol. 8:141.

Yin, Z., Tang, W., Wang, J., Liu, X., Yang, L., Gao, C., Zhang, J., Zhang, H., Zheng, X., Wang, P., and Zhang, Z. 2016. Phosphodiesterase MoPdeH targets MoMck1 of the conserved mitogen-activated protein (MAP) kinase signalling pathway to regulate cell wall integrity in rice blast fungus Magnaporthe oryzae. Mol. Plant Pathol. 17:654-668.

Yu, J., Chang, P.-K., Ehrlich, K. C., Cary, J. W., Bhatnagar, D., Cleveland, T. E., Payne, G. A., Linz, J. E., Woloshuk, C. P., and Bennett, J. W. 2004. Clustered pathway genes in aflatoxin biosynthesis. Appl. Environ. Microbiol. 70:1253-1262.
Yuan, J., Chen, Z., Guo, Z., Li, D., Zhang, F., Shen, J., Zhang, Y., Wang, S., and Zhuang, Z. 2018. PbsB regulates morphogenesis, aflatoxin B1 biosynthesis and pathogenicity of Aspergillus flavus. Front. Cell. Infect. Microbiol. 8:162

Zeng, F., Gong, X., Hamid, M. I., Fu, Y., Jiatao, X., Cheng, J., Li, G., and Jiang, D. 2012. A fungal cell wall integrity-associated MAP kinase cascade in Coniothyrium minitans is required for conidiation and mycoparasitism. Fungal Genet. Biol. 49:347-357.

Zhang, C., Wang, J., Tao, H., Dang, X., Wang, Y., Chen, M., Zhai, Z., Yu, W., Xu, L., Shim, W.-B., Lu, G., and Wang, Z. 2015. FvBck1, a component of cell wall integrity MAP kinase pathway, is required for virulence and oxidative stress response in sugarcane Pokkah Boeng pathogen. Front. Microbiol. 6:1096.

Zhang, F., Geng, L., Huang, L., Deng, J., Fasoyin, O. E., Yao, G., and Wang, S. 2018. Contribution of peroxisomal protein importer AflPex 5 to development and pathogenesis in the fungus Aspergillus flavus. Curr. Genet. 64:1335-1348.

Zhang, F., Guo, Z., Zhong, H., Wang, S., Yang, W., Liu, Y., and Wang, S. 2014. RNA-Seq-based transcriptome analysis of aflatoxigenic Aspergillus flavus in response to water activity. Toxins (Basel) 6:3187-3207.

Zhang, F., Xu, G., Geng, L., Lu, X., Yang, K., Yuan, J., Nie, X., Zhuang, Z., and Wang, S. 2016. The stress response regulator AflSkn7 influences morphological development, stress response, and pathogenicity in the fungus Aspergillus flavus. Toxins (Basel) 8:202.

Zhao, X., Mehrabi, R., and Xu, J.-R. 2007. Mitogen-activated protein kinase pathways and fungal pathogenesis. Eukaryot. Cell 6:1701-1714. 